\title{
DISCUSSION
}

\section{Applications of geosynthetics for soil reinforcement}

\author{
M. I. M. PINTO (2003) Ground Improvement, 7, No. 2, 61-72
}

\section{S. K. Shukla, Banaras Hindu University, India}

There are several application areas for geosynthetics to function as reinforcement. Many developments in this area have taken place recently. Therefore it is a challenging task to include full details of all related aspects in a single paper of limited length. The author of the paper has been successful in completing this task. He has presented most of the topics in a simple manner so that readers and users of geosynthetics can well understand the concepts involved. However, the discusser feels that there are a few important aspects that require more explanation, clarification or addition for the sake of the completeness of the concepts of geosynthetic reinforcement, as well as to enhance the usefulness of the paper.

Reinforcement and separation are two major functions to be served by geosynthetics when used in many applications. The discusser has found, as a consultant, that in field situations, it becomes a difficult task to decide whether the function to be served by a geosynthetic is reinforcement or separation, especially when it is being used in roads, rail tracks, foundations, and embankments. This key issue has not been discussed in the paper.

Nishida and Nishigata (1994) have suggested that separation can be an important function compared with reinforcement when the ratio of the applied stress $(\sigma)$ on the subgrade soil to the shear strength $\left(c_{\mathrm{u}}\right)$ of the subgrade soil has a low value (less than 8), and it is basically independent of the settlement of the reinforced soil system (Fig. 9).

The author has stated that reinforcement is a result of the transference of tensile stresses from the soil to the reinforcement owing to the friction developed between them. This statement is valid when geotextiles are being used, but it

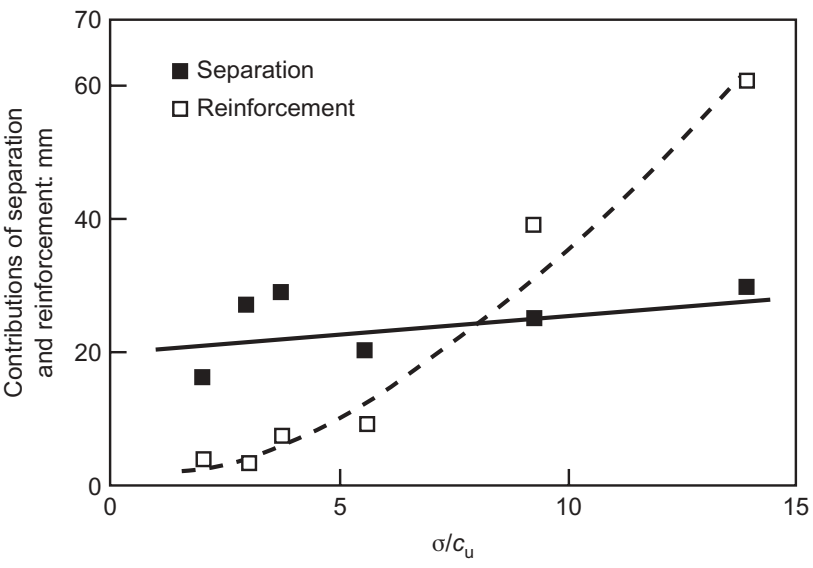

Fig. 9. Relationship between separation and the reinforcement functions (after Nishida and Nishigata, 1994) may be only partially true for geogrids, which also have an anchoring effect, as described below in this discussion.

Three mechanisms for soil reinforcement were stated as shear, anchorage and membrane, without much description. In the discusser's opinion, the reinforcement function of geosynthetics can conveniently be observed in terms of their roles, as described below, especially when they are being used in roads, rail tracks, foundations, and embankments.

A geosynthetic layer reduces the outward shear stresses transmitted from the overlying soil/fill to the top of the underlying foundation soil. This action of geosynthetics is known as the shear stress reduction effect. This effect results in a general rather than a local shear failure (Fig. 10(a)), thereby causing an increase in the load-bearing capacity of the foundation soil (Bourdeau et al., 1982; Guido et al., 1985; Love et al., 1987; Espinoza, 1994; Espinoza and Bray, 1995; Adams and Collin, 1997). The reduction in shear stress and the change in the failure mechanism are the primary benefits of the geosynthetic layer at small deformations.

A geosynthetic layer redistributes the applied surface load by providing restraint of the granular fill if embedded in it, or by providing restraint of the granular fill and the soft foundation soil, if placed at their interface, resulting in a reduction of applied stress (Fig. 10(b)). This is referred to as the slab effect or confinement effect of geosynthetics (Bourdeau et al., 1982; Giroud et al., 1984; Madhav and Poorooshasb, 1989; Sellmeijer, 1990; Hausmann, 1990). The friction mobilised between the soil and the geosynthetic layer plays an important role in confining the soil.

The deformed geosynthetic, sustaining normal and shear stresses, has a membrane force with a vertical component that resists applied loads: that is, the deformed geosynthetic provides a vertical support to the overlying soil mass subjected to loading. This action of geosynthetics is popularly known as its membrane effect (Fig. 10(c)) (Giroud and Noiray, 1981; Bourdeau et al., 1982; Sellmeijer et al., 1982; Love et al., 1987; Madhav and Poorooshasb, 1988; Bourdeau, 1989; Sellmeijer, 1990; Shukla and Chandra, 1994). Depending upon the type of stress (normal stress or shear stress) sustained by the geosynthetics during their action, the membrane support may be classified as normal stress membrane support or interfacial shear stress membrane support respectively (Espinoza and Bray, 1995). The edges of the geosynthetic layer are required to be anchored in order to develop the membrane support contribution resulting from normal stresses, whereas the membrane support contribution resulting from mobilised interfacial membrane shear stresses does not require any anchorage. The membrane effect of geosynthetics causes an increase in the load-bearing capacity of the foundation soil below the loaded area with a downward loading on its surface to either side of the loaded area, thus reducing its heave potential. Both geotextiles and geogrids can be effective in membrane action in the case of high deformation of reinforced foundation soils (Hass et al., 1988). 

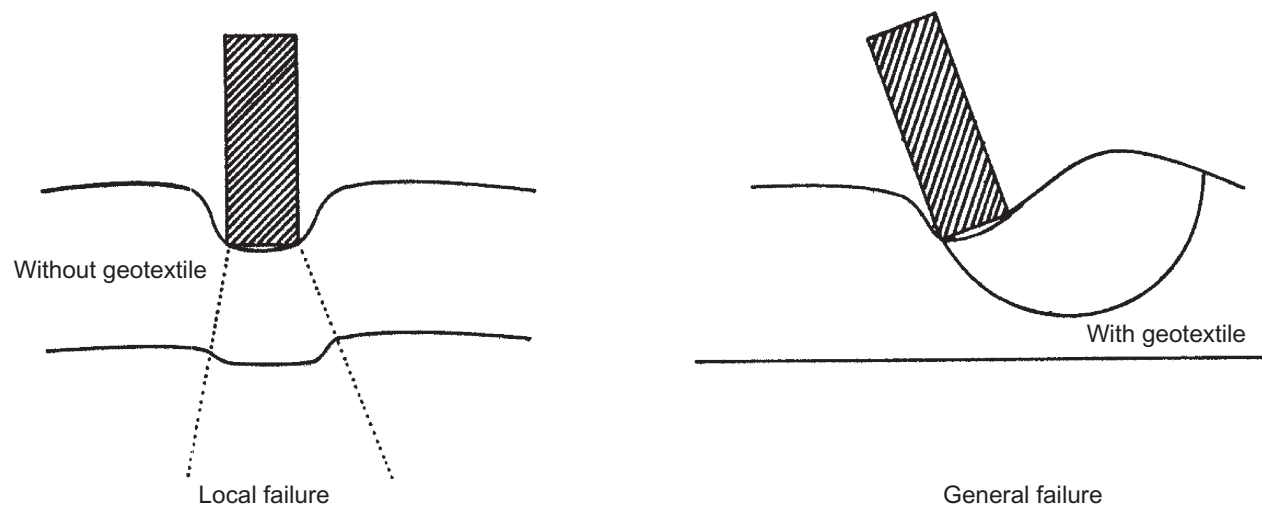

(a)

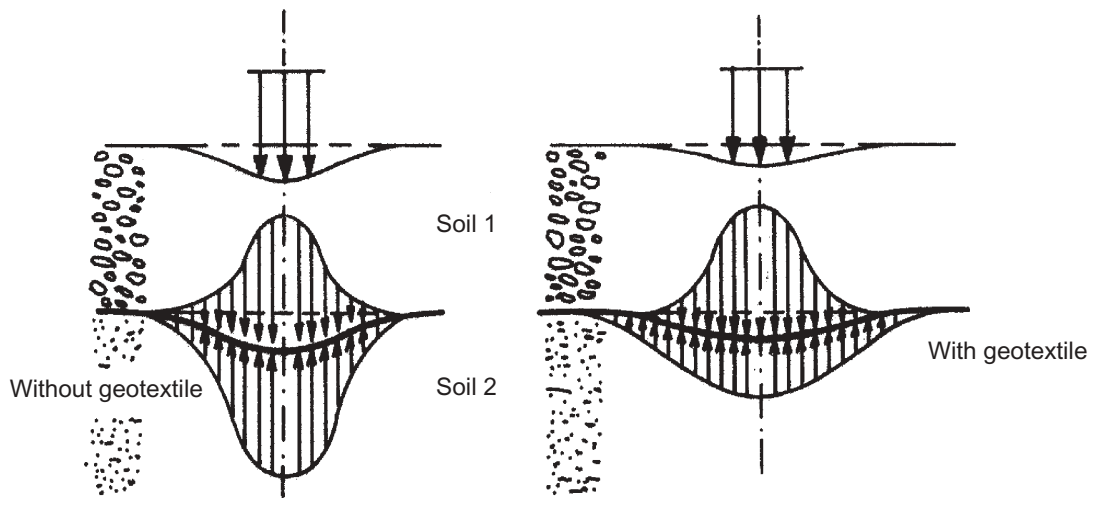

(b)
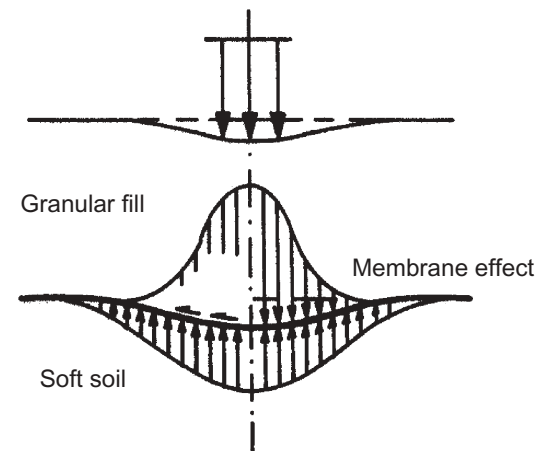

(c)

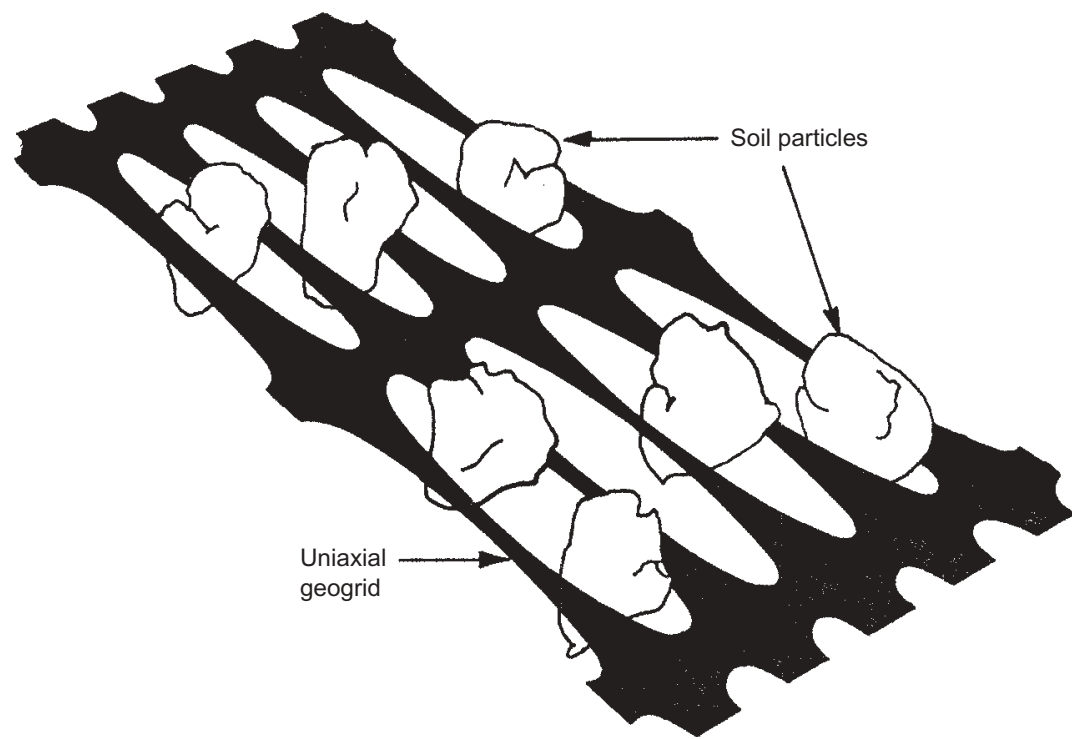

(d)

Fig. 10. Roles of a geosynthetic layer: (a) change of failure mode; (b) redistribution of applied surface load; (c) membrane effect (after Bourdeau et al., 1982; Espinoza, 1994); (d) anchoring effect. 
The use of geogrids has another benefit due to the interlocking of the soil through the apertures of the grid, known as the anchoring effect (Fig. 10(d)) (Guido et al., 1986). The transfer of stress from the soil to the geogrid reinforcement is made through bearing at the soil to the grid crossbar interface.

It is mentioned in the paper that, for a geosynthetic acting as reinforcement, the most important properties are the tensile strength, the tensile modulus and the interface shear strength. It is better to express the interface shear strength as frictional and interlocking characteristics or soil-geosynthetic interface characteristics. Creep and durability must also be added in the list of important properties of geosynthetics when functioning as reinforcement (Paulson, 1987; Shukla, 2002).

\section{Author's reply}

The author of the paper would like to thank the discusser for creating the opportunity for some important aspects to be clarified further. The objective of the paper was to give an overview of the different reinforcement applications for geosynthetics, and not to go deeper, owing to space limitations. However, the aspects referred to by the discusser are indeed very important as far as the reinforcement function of the geosynthetics is concerned, and therefore it is desirable to provide more explanation.

The author agrees that in many situations it is indeed very difficult to identify one dominant function over the other. However, separation depends on the grain size of the soils involved. Most low-strength foundation soils are composed of small particles, whereas the placed layers (for roads, railways, foundations and embankments) are of coarser materials. In these situations separation is always needed, quite independent from the ratio of the applied stress to the strength of the subgrade soil, as Fig. 9 clearly shows. Reinforcement will increase in importance as that ratio increases. Fortunately, separation and reinforcement are compatible functions. Furthermore, they work together, interacting: reinforcement reduces deformation and therefore reduces mixing of the particles (performing indirectly and to some extent the separation function); on the other hand, separation prevents mixing and consequently prevents progressive loss of strength of the subsequent layers. The ideal material to be used for roads, railways, foundations and embankments (i.e. when a coarser material is placed on top of a smaller-sized particle soil with low strength) would be a continuous material such as a high-strength geotextile or a composite of a stiffer geogrid combined with a geotextile. In this way, the necessary separation and reinforcement functions can be performed simultaneously.

Reinforcement is a result of transference of tensile stresses from the soil to the reinforcement due to friction. This is a traditional definition presented by Vidal in the 1960s (Vidal, 1966, 1969). Although yet suitable for geotextiles, it is not completely correct nowadays, with geogrids being used as a reinforcing material. As the discusser points out, and it was only very briefly mentioned in the paper (see the section 'Soil reinforcement interaction' on p. 63), for geogrids the interaction mechanism results not only from friction developed on the surface of the geogrid, but also from interlocking of the soil particles within the openings (as is shown in Fig. 10(d)). This interlocking is responsible for a concentration of stresses against the transverse bars of the geogrid. Owing to the small surface area and large apertures of geogrids, the interaction is due mainly to interlocking rather than to friction. However, an exception occurs when the soil particles are small. In this situation the interlocking effect is negligible because no passive strength is developed against the geogrid (as referred to by Sharma and Bolton, 1996).

The three mechanisms described in the paper (shear, anchorage and membrane) are concerned simply with the types of load that are supported by the reinforcement geosynthetic (shear: supports a planar load due to slide of the soil over the geosynthetics; anchorage: supports a planar load due to pull-out of the geosynthetics from the soil; membrane: supports both a planar and a normal load). Therefore no further explanation was found to be necessary. The discusser describes mechanisms that take into account the reinforcement action (i.e. how the reinforcement takes the stresses from the subgrade soil and which type of stresses are taken), which is a very important but completely different concept from the previous one. This new concept was in fact described in the paper (see section 'Roads and railways' on p. 63 , and referred to later as being similar for foundations), although not in as much detail as that described by the discusser:

. . as interaction develops between the aggregate layer and the geosynthetic, horizontal stresses are transferred from the aggregate layer to the geosynthetic, by friction, preventing these from being transmitted to the subgrade soil and therefore maintaining the full bearing capacity of the subgrade soil. Through the shear interaction mechanism the geosynthetic can therefore improve the performance of the system with very little or no rutting ...

This corresponds to mechanism I (shear stress reduction effect) described by the discusser. In the paper, the terms friction and shear are meant to include interlocking if the geosynthetic is a geogrid.

. If the subgrade soil is incompressible (e.g. saturated clay), its deformation causes heave between and beyond the loads (vehicle wheels) and the geosynthetic deforms in sympathy into a curved tension membrane ... The normal stress applied on its concave face is higher than the normal stress on its convex face. Therefore, since the membrane is in tension, there is a vertical upwards component of the membrane which acts to reduce the vertical stress under the wheels.

This, as far as the author understands, corresponds to both mechanism II and III (slab effect and membrane effect) described by the discusser.

Mechanism IV described by the discusser (anchorage effect) is in reality included in the previous mechanisms I and II, as it is related just to how the stresses are transferred from the top soil to the geosynthetic if this is a geogrid. The so called anchorage effect should in fact be expressed as interlocking effect to avoid confusion with anchorage (pullout).

To take clearly into account the particularity of the geogrids, and its interlocking effect, the expression interface shear strength might certainly be replaced by a more general term such as interface strength or interface characteristics, or simply soil-reinforcement interaction.

Creep is also very important in some applications, and this was in fact mentioned in the paper (see section 'Tensile properties of geosynthetics', p. 63). To take creep into consideration, the long-term properties should be used for design.

Durability is definitely important. In the paper it was not mentioned as an important characteristic, because the author's intention was to list the most important characteristics specifically for reinforcement (i.e. the intention was not to list those properties that are important for other functions 
than reinforcement). Durability during the design life of the geosynthetic is a very important property not just for all reinforcement applications, but also for all the other functions.

\section{References}

Adams M. T. and Collin J. G. (1997) Large model spread footing load tests on geosynthetic reinforced soil foundations. Journal of Geotechnical and Geoenvironmental Engineering, 123, No. 1, $66-72$.

BouRdEAU P. L. (1989) Modeling of membrane action in a two-layer reinforced soil system. Computers and Geotechnics, 7, 19-36.

Bourdeau P. L., Harr M. E. and Holtz R. D. (1982) Soil-fabric interaction: an analytical model. Proceedings of the 2nd International Conference on Geotextiles, Las Vegas, 387-391.

EspiNozA R. D. (1994) Soil-geotextile interaction: evaluation of membrane support. Geotextiles and Geomembranes, 13, 281-293.

EspinozA R. D. and Bray J. D. (1995) An integrated approach to evaluating single-layer reinforced soils. Geosynthetics International, 2, No. 4, 723-739.

Giroud J. P. and Noiray L. (1981) Geotextile-reinforced unpaved road design. Journal of Geotechnical Engineering, ASCE, 107, No. 9, 1233-1254

Giroud J. P., Ah-Line A. and Bonaparte R. (1984) Design of unpaved roads and trafficked areas with geogrids Proceedings of the Symposium on Polymer Grid Reinforcement, London, pp. $116-127$.

Guido V. A., Biesiadecki G. L. and Sullivan M. J. (1985) Bearing capacity of a geotextile-reinforced foundation. Proceedings of the 11th International Conference on Soil Mechanics and Foundation Engineering, San Francisco, 1777-1780.

Guido V. A., Dong K. G. and Sweeny A. (1986) Comparison of geogrid and geotextile reinforced earth slabs. Canadian Geotechnical Journal, 23, No. 1, 435-440.

Hass R., Walls J. and Carroll R. G. (1988) Geogrid reinforcement of granular bases in flexible pavements. Transportation ResearchRecord, No. 1188, 19-27.
Hausmann M. R. (1990). Engineering Principles of Ground Modification. McGraw-Hill, New York.

Love J. P., Burd H. J., Milligan G. W. E. and Houlsby G. T. (1987) Analytical and model studies of reinforcement of a layer of granular fill on soft clay subgrade. Canadian Geotechnical Journal, 24, 611-622.

Madhav M. R. and Poorooshasb H. B. (1988) A new model for geosynthetic-reinforced soil. Computers and Geotechnics, 6, $277-290$.

Madhav M. R. and Poorooshasb H. B. (1989) Modified Pasternak model for reinforced soil. Mathematical and Computational Modelling, An International Journal, 12, 1505-1509.

Nishida K. and Nishigata T. (1994) The evaluation of separation function for geotextiles. Proceedings of the 5th International Conference on Geotextiles, Geomembranes and Related Products, Singapore.

Paulson J. N. (1987) Geosynthetic material and physical properties relevant to soil reinforcement applications. Geotextiles and Geomembranes, 6, Nos 1-3, 211-223.

Sellmeijer J. B. (1990) Design of geotextile reinforced unpaved roads and parking areas. Proceedings of the 4th International Conference on Geotextiles, Geomembranes and Related Products, The Hague, 177-182

Sellmeijer J. B., Kenter C. J. and Van den Berg C. (1982) Calculation method for fabric reinforced road. Proceedings of the 2nd International Conference on Geotextiles, Las Vegas, 393-398.

Sharma J. S. and Bolton M. D. (1996) Centrifuge modelling of reinforced embankments on soft clay reinforced by geogrids. Geotextiles and Geomembranes, 14, 1-17

SHUKLA S. K. (2002) Fundamentals of geosynthetics. In Geosynthetics and Their Applications (ed. S. K. Shukla). Thomas Telford, London, pp. 1-54.

ShuKLa S. K. and Chandra S. (1994) A generalized mechanical model for geosynthetic-reinforced foundation soil. Geotextiles and Geomembranes, 13, No. 12, 813-825.

Vidal H. (1966) La terre armee. Annales de L'Institute du Batiment et des Travaux Publics, 223-224, 888-938.

Vidal H. (1969) The principle of reinforced earth. Highway Research Record, No. 282, 1-16. 